\title{
Added sugars drive chronic kidney disease and its consequences: A comprehensive review
}

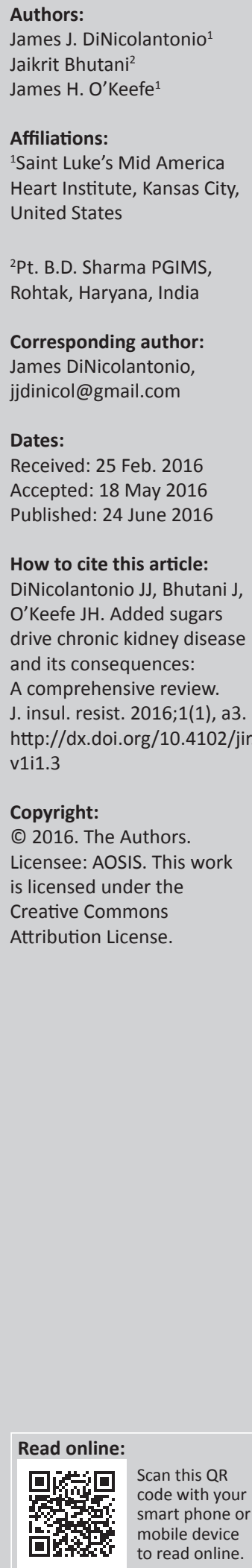

\begin{abstract}
The consumption of added sugars (e.g. sucrose [table sugar] and high-fructose corn syrup) over the last 200 years has increased exponentially and parallels the increased prevalence of chronic kidney disease (CKD). Data for animals and humans suggest that the consumption of added sugars leads to kidney damage and related metabolic derangements that increase cardiovascular risk. Importantly, the consumption of added sugars has been found to induce insulin resistance and increase uric acid in humans, both of which increase the conversion of glucose to fructose (i.e. fructogenesis) via the polyol pathway. The polyol pathway has recently been implicated in the contribution and progression of kidney damage, suggesting that even glucose can be toxic to the kidney via its endogenous transformation into fructose in the proximal tubule. Consuming added fructose has been shown to induce insulin resistance, which can lead to hyperglycaemia, oxidative stress, inflammation and the activation of the immune system, all of which can synergistically contribute to kidney damage. CKD guidelines should stress a reduction in the consumption of added sugars as a means to prevent and treat CKD as well as reduce CKD-related morbidity and mortality.
\end{abstract}

\section{Introduction}

There has been an exponential increase in chronic kidney disease (CKD) in the United States (US), with a fourfold increase in the prevalence of end-stage renal disease between 1980 and $2002 .{ }^{1}$ Worldwide CKD is known to affect $14 \%$ of the total population. ${ }^{2}$ The 2010 Global Health Burden study ranked CKD as the 18th largest cause of total deaths worldwide, which rose from 27 th in $1990.3,4$ Along with this growing CKD burden, the consumption of added sugars (high-fructose corn syrup and sucrose) has also grown dramatically in the US. The intake of refined sugar went from 4 pounds per person per year in the US in 1776 to 120 pounds of added sugars in 2002.5,6,7 Much of the increase in the intake of added sugars has come in the form of sugar-sweetened beverages. ${ }^{8}$

The kidney dysfunction resulting from diabetes, known as diabetic kidney disease (DKD), is the leading cause of CKD. Additionally, hypertension is a direct cause of CKD, and the excess consumption of added sugars has been implicated as a direct cause of both diabetes and hypertension. ${ }^{6,9,10}$ The International Diabetes Federation Diabetes Atlas 7th edition estimates the number of adult diabetics worldwide at 415 million ( 1 in 11 adults), and this is expected to increase to 642 million by 2040. ${ }^{11}$ Additionally, along with an enormous economic health burden (\$612 billion), diabetes causes 1 death every $6 \mathrm{~s} .{ }^{11}$ The prevalence of DKD, as estimated by the Developing Education on MA for Awareness of renal and cardiovascular risk iN Diabetes (DEMAND) study (2006) in 33 countries, was 22,39 and $10 \%$ in adults as shown by the presence of impaired renal function (eGFR $<60 \mathrm{~mL} / \mathrm{min} / 1.73 \mathrm{~m}^{2}$ ), microalbuminuria and macroalbuminuria, respectively, with a particularly high prevalence of albuminuria among Asian and Hispanic patients. ${ }^{12}$ The estimated mortality burden in 2013 indicated that patients with CKD without diabetes had an adjusted mortality rate of 52 deaths per 1000 patient-years at risk, whereas those with DKD had 3 times the mortality, at 155 deaths per 1000 patient-years. ${ }^{2}$ Furthermore, the Medicare expenditure for this CKD burden was estimated to be $\$ 50$ billion in 2013 , representing $20 \%$ of the total medical expense of U.S. adults aged 65 years or older. ${ }^{2}$

\section{Fructose metabolism}

Fructose is a naturally occurring sugar, found in fruits, honey, sugar cane and sugar beet. It forms a major part of the human diet, both directly and indirectly. Fifty percent of table sugar (also known as sucrose) is composed of fructose. High-fructose corn syrup (HFCS), another commonly consumed sugar, generally contains 55\% fructose and is found in a variety of food products including fruit juices and sodas, as well as processed foods like ketchup, power bars, candy and cereals. ${ }^{6,13}$ 
Fructose is absorbed at a slower rate than glucose. ${ }^{14}$ Its absorption occurs passively and actively via GLUT- 5 on the brush-border membrane of the lower part of the duodenum and jejunum, and is transported into the circulation by GLUT-2. ${ }^{14,15}$ Once fructose is absorbed it is taken up by the liver via GLUT-2. ${ }^{15}$ Much of the ingested fructose goes through first-pass metabolism in the liver, where fructokinase converts fructose to fructose-1-phosphate. ${ }^{15}$

Fructose metabolism differs from that of glucose metabolism as the trioses produced from fructose lack phosphate and need to be phosphorylated for mitochondrial oxidation. ${ }^{16}$ Additionally, unlike glucose, the metabolism of fructose is not regulated by insulin. Moreover, glucokinase has a much higher $\mathrm{Km}$ for glucose compared to the $\mathrm{Km}$ of fructokinase for fructose. ${ }^{15}$ Thus, the metabolism of fructose, as compared to glucose, is much more rapid, leading to intracellular adenosine triphosphate (ATP) depletion. ${ }^{17,18}$ Much of the triose-phosphates produced from fructose metabolism are then converted into glucose and glycogen via gluconeogenesis. ${ }^{15}$

Under normoglycaemia, only 3\% of glucose is metabolised by the polyol pathway. ${ }^{14,19}$ However, during hyperglycaemic conditions (i.e. blood glucose $>126 \mathrm{mg} / \mathrm{dL}$ ) this increases to more than $30 \% .^{19,20}$ The polyol pathway is also increased with hyperuricemia. ${ }^{21}$ Consumption of added sugars (which contain fructose) undoubtedly increases fructogenesis (the endogenous production of fructose from glucose) by promoting insulin resistance and subsequent hyperglycemia, 22,23 as well as hyperuricemia, all of which activates the polyol pathway. ${ }^{21}$ An increase in the polyol pathway can lead to oxidative stress ${ }^{24}$ by depleting NADPH when glucose is first converted to sorbitol in the first step of the pathway (because of a reduction in glutathione levels). ${ }^{25}$

Additionally, oxidative stress is generated during the second step of the polyol pathway (conversion of sorbitol into fructose), causing the cofactor $\mathrm{NAD}^{+}$to be converted to $\mathrm{NADH}$ by sorbitol dehydrogenase (SDH). As NADH is a substrate for NADH oxidase, this increases the production of superoxide anions..$^{24,26}$ Finally, the endogenously produced fructose can be further metabolised into fructose-3phosphate, 3-deoxyglucosone and methylglyoxal, ${ }^{27}$ which leads to non-enzymatic glycation reactions, even more so than glucose or fructose (despite much lower concentrations compared to glucose). ${ }^{28,29}$ Thus, fructose metabolites are likely more relevant in the formation of advanced glycation end products (AGEs). ${ }^{29}$ AGEs, formed from the nonenzymatic reaction of sugars with proteins, lipids and nuclear acids, are constantly building up within the body, particularly in diabetics. Their binding with receptor for advanced glycation end products (RAGEs) leads to proxidant and proinflammatory reactions. ${ }^{30}$ An increase in the metabolism of fructose (via activation of the polyol pathway - as well as increased consumption of dietary fructose) will inevitably lead to increased AGE formation and subsequent elevation in reactive oxygen species (ROS) generation. ${ }^{24}$ It is well-known that diabetics have increased oxidative stress manifested as elevated levels of oxidised DNA, proteins and lipids. ${ }^{31}$ This is likely caused by the activation of the polyol pathway and the subsequent damaging effects of glucose being converted to sorbitol and fructose. ${ }^{24}$ Indeed, sorbitol cannot cross cellular membranes and may create hypertonic conditions within tissues, leading to microvascular complications and further activation of the polyol pathway. ${ }^{32}$

These abnormalities are also perpetuated by hyperglycaemia, which can lead to oxidative stress via the production of superoxide in the mitochondria (through excess energetic substrates in the electron transport chain, leading to inadequate buffering of free radical intermediates), ${ }^{33}$ autooxidation of glucose ${ }^{34}$ and through the formation of $\mathrm{AGEs}^{35}$ (as well as through the interaction between AGEs and RAGEs). ${ }^{24,36}$ Additionally, glycation of superoxide dismutase can decrease antioxidant defence systems through inactivation of antioxidant enzymes. ${ }^{37,38}$ Thus, AGE formation likely plays a major role in fructose-induced oxidative stress.

When the polyol pathway is upregulated, this sets the stage for increased damage in the body from the consumption of refined carbohydrates (e.g., starch - providing just glucose or sucrose/HFCS - providing fructose + glucose); as more glucose is converted to fructose. In essence, the overconsumption of added fructose induces a state where the consumption of glucose and starch becomes even more harmful - by shunting more glucose towards fructogenesis with subsequent harmful metabolic pathways (and intermediates) that follow. As glucose can be converted to fructose (fructogenesis) via the polyol pathway in multiple tissues, including the eyes, testis, liver, placenta, ovary, kidney, erythrocyte, cardiac and skeletal muscle, and the brain, ${ }^{24}$ the harms of consuming fructose-containing added sugars (e.g. HFCS and sugar) likely extends beyond the kidney.

It is generally thought that fructose metabolism does not occur to a significant degree in extrahepatic cells. ${ }^{15}$ This belief comes from short-term feeding studies looking at fructose concentrations in the plasma. However, multiple metabolic states increase the absorption of fructose (e.g. diabetes, hyperglycaemia, hyperuricemia, ischemia), ${ }^{21,39}$ especially with continued consumption (inducing epigenetic changes leading to upregulation of its own absorption transporter, ${ }^{40}$ leading to enhanced fructose absorption). Hence, longer trials would undoubtedly show much higher levels of plasma fructose compared to acute-feeding studies. Additionally, multiple cells throughout the body can convert glucose to fructose, ${ }^{8}$ and thus the extent of fructose metabolism (via the polyol pathway) in extrahepatic cells is likely greatly underestimated, especially in those who are insulinresistant. ${ }^{21,39}$ Moreover, GLUT-5 receptors are found in the small intestine, testis, kidney, skeletal muscle and adipose tissue, indicating that fructose uptake and subsequent metabolism in these tissues may also lead to significant metabolic derangements. ${ }^{41,42}$ Fructose is elevated in the serum 
of diabetic patients, probably because of a number of factors, including increased fructose consumption but also insulin resistance and enhanced fructose absorption. Indeed, insulin resistance can lead to the loss of GLUT-5 in adipocytes (decreases in GLUT-5 surface density, and decreases in fructose transport and utilisation rates) - decreasing the shunting of fructose into adipocytes, with more being available to other tissues. Indeed, kidney GLUT-5 levels are not reduced in number with insulin resistance, and thus would likely be exposed to a greater influx of fructose and subsequent metabolic harms of its metabolism. ${ }^{27}$

\section{Fructose and the kidney}

Despite similar levels of hyperglycaemia and haemoglobin A1c (A1c) in streptozotocin-induced diabetic mice, the inability of mice to metabolise fructose leads to improved renal function and less renal injury. ${ }^{21}$ This was found even though the diet lacked fructose, indicating that endogenous fructose production and its subsequent metabolism is indeed harmful to the kidney. The study compared the differences between the metabolic profile of khk-/- (mice lacking fructokinase-ketohexokinase) and wild-type mice. Mice lacking the ability to metabolise fructose (khk-/-) had improved tubular function [measured by lower fractional excretion of phosphate], kidney/body weight ratio, body weight, serum creatinine levels, blood urea nitrogen (BUN) levels and creatinine clearance. There were also fewer enlargements of tubular luminal areas, collagen III deposition (a marker of interstitial collagen) and tubular injury (loss of brush border area and N-acetyl-b-D-glucosaminidase, a biomarker of tubular injury). ${ }^{21}$ Despite the fact that fructose is not metabolised in the glomeruli, there was also glomerular protection indicated by reduced glomerular size and less glomerular expansion and less mesangial collagen IV deposition, and likely a reduction in glomerular permeability to protein or improved proximal tubular function (indicated by less urinary albumin excretion). Additionally, non-renal measurements, such as serum triglycerides, cholesterol and uric acid, tended to be lower in diabetic mice lacking the ability to metabolise fructose. This suggests that fructose metabolism plays a role in diabetic dyslipidaemia. The inability of diabetic mice to metabolise fructose protects them from renal damage ${ }^{21}$ supporting the notion that fructokinase is a promoter of DKD, at least in mice. ${ }^{21}$ This was despite a similar degree of diabetes (hyperglycaemia and A1c) between mice that could and could not metabolise fructose and a lack of fructose in the diet. Increased sorbitol and fructose concentrations in the kidney may be novel biomarkers for risk of renal damage. ${ }^{21}$ In summary, fructose derived from the diet or from the polyol pathway (endogenous conversion from glucose) is a nephrotoxin. ${ }^{11}$ Indeed, feeding rats fructose leads to tubulointerstitial injury ${ }^{43}$ and accelerates the progression of $\mathrm{CKD}^{44}$ which was not seen with dextrose. ${ }^{44}$

Fructose-induced ATP depletion and uric acid generation leads to oxidative stress and inflammation in tubular cells. ${ }^{21,45}$ This may be caused by an increase in renal cortical levels of superoxide. ${ }^{21}$ Cells that are exposed to high glucose levels activate aldose reductase, increasing the formation of sorbitol and fructose from glucose. ${ }^{21}$ The endogenous production of fructose from glucose (fructogenesis), and the subsequent reduction in ATP and increase in uric acid, contributes to high glucose-induced inflammation (inflammatory cytokine and chemokine expression) and increased macrophage infiltration in the kidney. ${ }^{21}$ As diabetic nephropathy is associated with the presence of macrophage in the glomeruli and the interstitium, ${ }^{21,46}$ fructogenesis could be a contributor. ${ }^{21}$ Additionally, the elevation in uric acid found with dietary fructose or fructogenesis may activate aldose reductase, increasing sorbitol accumulation. This was shown in mice that were able to metabolise fructose. ${ }^{21}$ As sorbitol is impermeable to cellular membranes, its increase may lead to osmotic damage and cell death. ${ }^{30}$

Fatty acids are a major source of energy (ATP) for kidney cells. ${ }^{16,47,48}$ As fructose can induce insulin resistance, ${ }^{22,23,49}$ which prevents fatty acids from being utilised by the body when insulin levels are elevated, ${ }^{50}$ this may also lead to kidney cell damage. Proximal kidney damage induced by fructose may also lead to glomerular damage. Indeed, the tubular damage could cause reflex arteriolar vasodilation causing increased glomerular pressure. ${ }^{21,51,52}$ Repeated damage to the proximal tubule is proposed as a mechanism for promoting diabetic nephropathy, and fructose may be the causative factor. ${ }^{21,53}$

Aldose reductase is increased in diabetes. ${ }^{24}$ In animal models of diabetes, aldose reductase inhibitors (ARIs) prevent hyperglycaemia-induced increases in sorbitol levels in the glomerulus. An over-activation of aldose reductase is linked with kidney disease, AGEs, and ROS. Furthermore, a deficiency in aldose reductase seems to prevent the development of nephropathy in animal models of diabetes. What all of this suggests is that activation of aldose reductase in the kidney contributes to diabetic nephropathy as well as other complications. ${ }^{24}$

When aldose reductase is upregulated, nicotinamide adenine dinucleotide phosphate (NADPH) gets depleted upon glucose conversion to sorbitol. ${ }^{30}$ Since NADPH acts as a cofactor for regenerating intracellular glutathione in cells, its depletion leads to a reduction in the antioxidant capacity of the cells and a reduction in protection from oxidative stress. ${ }^{30}$ Fructose produced from the polyol pathway can lead to the production of fructose-3-phosphate and then 3-deoxyglucosone, which can then result in the production of AGEs. ${ }^{54}$ The metabolism of sorbitol by SDH alters the $\mathrm{NADH} / \mathrm{NAD}+$ ratio, which likely increases the production of ROS by stimulating NADH oxidase. ${ }^{30}$ In type 2 diabetes, postprandial fructose levels are associated with retinopathy, ${ }^{55}$ and animal data have shown that fructose is the component of sucrose that leads to retinopathy. ${ }^{56}$ Aldose reductase is involved in the development of diabetic retinopathy and the use of ARIs have been found to prevent or reduce diabetic retinopathy. ${ }^{30}$ Thus, a total shut down of the polyol pathway is likely more beneficial than simply inhibiting fructokinase. 
The consumption of fructose causes renal injury in animals, ${ }^{43,44,57}$ and fructose or sucrose feeding causes diffuse glomerulosclerosis, diabetic microangiopathy, intercapillary glomerulosclerosis and neuropathy in rodents. ${ }^{58,59,60}$ Nondiabetic rats given diets containing or yielding fructose had an increased kidney weight to body weight than those fed glucose, with the higher the level of fructose ingestion leading to a greater increase in the ratio. ${ }^{61}$ Additionally, the non-diabetic rats given glucose were free from renal pathological lesions, whereas most rats ingesting fructose or sucrose diets developed diffuse glomerulosclerosis and/ or tubular atrophy. Thus, the fructose moiety of sucrose is responsible for renal damage in rats fed sucrose ${ }^{61}$ Indeed, in rats pure fructose has been found to cause kidney hypertrophy, glomerular hypertension, cortical vasoconstriction and arteriolopathy of preglomerular vessels. $^{62}$

\section{Effects of fructose on kidney function in humans}

Initially in 2008, a cross-sectional analysis using data from the National Health and Nutrition Examination Survey (NHANES), 1999-2004, representing United States population sample, described the possible link between sugar-rich soda consumption and albuminuria. It concluded that weighted albuminuria ( $>17 \mathrm{mg} / \mathrm{g}$ in males and $>25 \mathrm{mg} / \mathrm{g}$ in females) prevalence was $11 \%$ and $17 \%$ in those who consumed more than two sugary soda drinks per day. ${ }^{63}$ The associations between albuminuria and soda consumption was modified by gender $(p=0.008)$ and overweight/obesity $(p=0.014)$. The odds ratio among women was 1.86 , however in males it was insignificant. Sodas not containing sugar (diet sodas) were not associated with albuminuria. ${ }^{63}$ Several other studies (case-control, cross-sectional and prospective cohort) have found that consuming anywhere from 1 to 2 or more sodas per day is associated with kidney disease or worsening kidney function (as measured by diagnosed kidney disease, estimated glomerular filtration $<60 \mathrm{~mL} / \mathrm{min}$, urine albuminto-creatinine ratio, albuminuria and estimated glomerular filtration rate decline of $\geq 30 \%) .{ }^{64,65,66}$

Apart from direct effects on the kidney, there is a significant amount of evidence describing persistent ongoing inflammation in patients with metabolic syndrome who have varying degrees of kidney function. ${ }^{67}$ Fructose has been shown to induce an inflammatory response because of its metabolism by ketohexokinase in the proximal tubule. ${ }^{45}$ Similarly, fructose has been shown to upregulate intracellular adhesion molecule (ICAM-1) in cultured human aortic endothelial cells, causing endothelial dysfunction adding to ongoing inflammation, which was not the case with glucose..$^{57}$ Thus, a proinflammatory milieu induced by fructose consumption may be a principal driver of CKD in humans. However, more clinical trials are needed.

Brymora et al. conducted a pilot study to observe the effects of lowering fructose intake in patients with Stage 2 and Stage
3 CKD (mean eGFR $47 \mathrm{~mL} / \mathrm{min} / 1.73 \mathrm{~m}^{2}$ ). They compared 28 patients (age $59 \pm 15$ years, 17 males and 11 females) who were switched from a basal fructose diet $(60.0 \mathrm{~g} / 24 \mathrm{~h})$ to a reduced $(12.0 \mathrm{~g} / 24 \mathrm{~h})$ fructose diet for 6 weeks. ${ }^{68}$ They were then resumed on their regular diet for another 6 weeks. Some critically important findings on the low-fructose diet versus the basal diet included lower serum uric acid $(6.6 \pm 1.0 \mathrm{mg} /$ $\mathrm{dL}$ vs. $7.1 \pm 1.3, p<0.1)$ and significantly reduced fasting serum insulin $(8.2 \pm 2.9$ vs. $11.2 \pm 6.1 \mathrm{mIU} / \mathrm{mL}, p<0.05)$. The levels of high sensitivity C-reactive protein (hsCRP) and soluble intercellular adhesion molecule (sICAM) were also significantly reduced with reduction in fructose intake. Importantly, creatinine clearance was higher and proteinuria was lower in the low-fructose diet versus the regular diet $\left(45 \mathrm{~mL} / \mathrm{min} / 1.73 \mathrm{~m}^{2}\right.$ vs. $39 \mathrm{~mL} / \mathrm{min} / 1.73 \mathrm{~m}^{2}$, and $0.12 \mathrm{~g} / 24$ h vs. 0.05 g/24 h). ${ }^{68}$ Although differences regarding kidney endpoints were not statistically significant, the trend for benefit in just 6 weeks is rather promising. Therefore, larger and longer clinical trials should be performed lowering the intake of added fructose to establish the effects in patients with CKD. Box 1 summarises plausible mechanisms of fructose-induced kidney damage and Box 2 provides final summaries.

\section{Conclusion}

A reduction in added sugars should be stressed as a dietary modification to prevent and treat CKD and its complications. This helps to prevent worsening kidney function and also protects against other complications such as diabetes, the metabolic syndrome and cardiovascular disease. The fructose

BOX 1: Plausible mechanisms of fructose-induced kidney damage.

Promotes insulin resistance, hyperglycaemia and hyperuricemia.

Activates the polyol pathway increasing the formation of sorbitol and fructose from glucose. Sorbitol leads to osmotic damage and cell death.

Creates insulin-resistant adipocytes leading to further hyperglycaemia and elevations in fructose levels.

Reduces fatty acid utilisation by the kidneys because of insulin resistance.

Leads to oxidative stress by:

- Reducing glutathione levels.

- Increasing the production of superoxide anions via the polyol pathway. - ATP depletion and uric acid generation.

Produces proinflammatory and pro-oxidant advanced glycation end products. Increases macrophage infiltration in the kidney.

\section{BOX 2: Final summaries.}

The increase in the consumption of added sugars, particularly sugar-sweetened beverages has paralleled the rise in chronic kidney disease in the Western world. The fructose moiety of sucrose is more responsible for renal damage than glucose and is likely a direct cause of diabetic nephropathy (causes direct damage to proximal tubule and indirect damage to the glomerulus).

Fructose exerts oxidative stress in the kidney via glutathione depletion, increased aldose reductase activity (activation of the polyol pathway), ATP depletion and uric acid generation, thus accelerating kidney complications.

Fructose or sucrose (i.e. table sugar) is worse than dextrose or glucose in causing kidney damage.

Fructokinase is a promoter of diabetic kidney disease.

By activating the polyol pathway (shunting more glucose towards fructogenesis) fructose makes dietary glucose (starch) more harmful.

Sorbitol and fructose levels in the kidney may be used as novel biomarkers to predict CKD risk.

Several other studies (case-control, cross-sectional and prospective cohort) have found that consuming anywhere from 1 to 2 or more sodas per day is associated with kidney disease or worsening kidney function. 
moiety in sucrose seems to be a more nephrotoxic culprit than the glucose. CKD guidelines should recommend for a limited consumption of added fructose.

\section{Acknowledgements Competing interests}

The authors declare that they have no financial or personal relationships which may have inappropriately influenced them in writing this article.

\section{Authors' contributions}

J.D. performed the initial data search and wrote the initial manuscript. J.B. and J.H.O'K. wrote parts of the manuscript. All authors approved the final version of the manuscript.

\section{References}

1. Johnson RJ, Segal MS, Sautin Y, et al. Potential role of sugar (fructose) in the epidemic of hypertension, obesity and the metabolic syndrome, diabetes, kidney disease, and cardiovascular disease. Am J Clin Nutr. 2007;86(4):899-906.

2. Available from: http://www.usrds.org/2015/view/v1_03.aspx

3. Available from: http://www.worldkidneyday.org/faqs/chronic-kidney-disease/

4. Jha V, Garcia-Garcia G, Iseki K, et al. Chronic kidney disease: Global dimension and perspectives. Lancet. 2013;382(9888):260-272. http://dx.doi.org/10.1016/S01406736(13)60687-X

5. Bray GA, Popkin BM. Dietary sugar and body weight: Have we reached a crisis in the epidemic of obesity and diabetes?: Health be damned! Pour on the sugar Diabetes Care. 2014;37(4):950-956. http://dx.doi.org/10.2337/dc13-2085

6. DiNicolantonio JJ, Lucan SC. The wrong white crystals: Not salt but sugar as aetiological in hypertension and cardiometabolic disease. Open Heart. 2014;1. http://dx.doi.org/10.1136/openhrt-2014-000167

7. Available from: http://www.ers.usda.gov/data-products/food-availability-(percapita)-data-system/food-availability-documentation.aspx).

8. Karalius VP, Shoham DA. Dietary sugar and artificial sweetener intake and chronic kidney disease: A review. Adv Chronic Kidney Dis. 2013;20(2):157-164. http:// dx.doi.org/10.1053/j.ackd.2012.12.005

9. DiNicolantonio JJ, Lucan SC, O'Keefe JH. An unsavory truth: Sugar, more than salt, predisposes to hypertension and chronic disease. Am J Cardiol. 2014;114(7): 1126-1128. http://dx.doi.org/10.1016/j.amjcard.2014.07.002

10. DiNicolantonio JJ, O'Keefe JH, Lucan SC. Added fructose: A principal driver of type 2 diabetes mellitus and its consequences. Mayo Clin Proc. 2015;90(3):372-381. http://dx.doi.org/10.1016/j.mayocp.2014.12.019

11. Available from: http://www.diabetesatlas.org/

12. Parving HH, Lewis JB, Ravid M, Remuzzi G, Hunsicker LG. Prevalence and risk factors for microalbuminuria in a referred cohort of type II diabetic patients: A global perspective. Kidney Int. 2006;69(11):2057-2063. http://dx.doi.org/10.1038 /sj.ki.5000377

13. Bray GA. Fructose: Pure, white, and deadly? Fructose, by any other name, is a health hazard. J Diabetes Sci Technol. 2010;4(4):1003-1007. http://dx.doi. org/10.1177/193229681000400432

14. Sun SZ, Empie MW. Fructose metabolism in humans - What isotopic tracer studies tell us. Nutr Metab (Lond). 2012;9(1):89. http://dx.doi.org/10.1186/1743-70759-89

15. Tappy L, Le KA. Metabolic effects of fructose and the worldwide increase in obesity. Physiol Rev. 2010;90(1):23-46. http://dx.doi.org/10.1152/physrev.00019.2009

16. Beckerman P, Susztak K. Sweet debate: Fructose versus glucose in diabetic kidney disease. J Am Soc Nephrol. 2014;25:2386-2388. http://dx.doi.org/10.1681/ASN. 2014050433

17. Van den Berghe G. Fructose: Metabolism and short-term effects on carbohydrate and purine metabolic pathways. Prog Biochem Pharmacol. 1986;21:1-32.

18. Johnson RJ, Gold MS, Johnson DR, et al. Attention-deficit/hyperactivity disorder: Is it time to reappraise the role of sugar consumption? Postgrad Med 2011;123(5):39-49. http://dx.doi.org/10.3810/pgm.2011.09.2458

19. Morrison AD, Clements RS, Jr., Travis SB, Oski F, Winegrad Al. Glucose utilization by the polyol pathway in human erythrocytes. Biochem Biophys Res Commun. 1970;40(1):199-205. http://dx.doi.org/10.1016/0006-291X(70)91066-1

20. Gonzalez RG, Barnett P, Aguayo J, Cheng HM, Chylack LT, Jr. Direct measurement of polyol pathway activity in the ocular lens. Diabetes. 1984;33(2):196-199. http:// dx.doi.org/10.2337/diab.33.2.196

21. Lanaspa MA, Ishimoto T, Cicerchi $C$, et al. Endogenous fructose production and fructokinase activation mediate renal injury in diabetic nephropathy. J Am Soc Nephrol. 2014;25:2526-2538. http://dx.doi.org/10.1681/ASN.2013080901
22. Beck-Nielsen H, Pedersen O, Lindskov HO. Impaired cellular insulin binding and insulin sensitivity induced by high-fructose feeding in normal subjects. Am J Clin Nutr. 1980;33(2):273-278.

23. Stanhope KL, Schwarz JM, Keim NL, et al. Consuming fructose-sweetened, not glucose-sweetened, beverages increases visceral adiposity and lipids and decreases insulin sensitivity in overweight/obese humans. J Clin Invest. 2009;119(5):1322-1334. http://dx.doi.org/10.1172/JCl37385

24. Tang WH, Martin KA, Hwa J. Aldose reductase, oxidative stress, and diabetic mellitus. Front Pharmacol. 2012;3:87. http://dx.doi.org/10.3389/fphar.2012.00087

25. Cheng HM, Gonzalez RG. The effect of high glucose and oxidative stress on lens metabolism, aldose reductase, and senile cataractogenesis. Metabolism. 1986;35(4 Suppl 1):10-14. http://dx.doi.org/10.1016/0026-0495(86)90180-0

26. Morre DM, Lenaz G, Morre DJ. Surface oxidase and oxidative stress propagation in aging. J Exp Biol. 2000;203(Pt 10):1513-1521.

27. Yan SF, Ramasamy R, Naka Y, Schmidt AM. Glycation, inflammation, and RAGE: A scaffold for the macrovascular complications of diabetes and beyond. Circ Res. 2003;93(12):1159-1169. http://dx.doi.org/10.1161/01.RES.0000103862.26506.3D

28. Hamada $\mathrm{Y}$, Araki N, Horiuchi S, Hotta N. Role of polyol pathway in nonenzymatic glycation. Nephrol Dial Transplant. 1996;(11 Suppl 5):95-98. http://dx.doi.org/ glycation. Nephrol Dial Tra
$10.1093 /$ ndt/11.supp5.95

29. Hamada Y, Araki N, Koh N, Nakamura J, Horiuchi S, Hotta N. Rapid formation of advanced glycation end products by intermediate metabolites of glycolytic pathway and polyol pathway. Biochem Biophys Res Commun. 1996;228(2):539543. http://dx.doi.org/10.1006/bbrc.1996.1695

30. Tarr JM, Kaul K, Chopra M, Kohner EM, Chibber R. Pathophysiology of diabetic retinopathy. ISRN Ophthalmology. 2013;2013:343560. http://dx.doi.org/10.1155 $/ 2013 / 343560$

31. Wiernsperger NF. Oxidative stress as a therapeutic target in diabetes: Revisiting the controversy. Diabetes Metab. 2003;29(6):579-585. http://dx.doi.org/10.1016 /S1262-3636(07)70072-1

32. Available from: https://en.wikipedia.org/wiki/Polyol_pathway.

33. Nishikawa T, Edelstein $\mathrm{D}, \mathrm{Du} \mathrm{XL}$, et al. Normalizing mitochondrial superoxide production blocks three pathways of hyperglycaemic damage. Nature. 2000;404 (6779):787-790. http://dx.doi.org/10.1038/35008121

34. Wolff SP, Dean RT. Glucose autoxidation and protein modification. The potential role of 'autoxidative glycosylation' in diabetes. Biochem. J. 1987;245(1):243-250. http://dx.doi.org/10.1042/bj2450243

35. Kennedy AL, Lyons TJ. Glycation, oxidation, and lipoxidation in the development of diabetic complications. Metabolism. 1997;46(12 Suppl 1):14-21. http://dx.doi. org/10.1016/S0026-0495(97)90311-5

36. Schmidt AM, Hori O, Brett J, Yan SD, Wautier JL, Stern D. Cellular receptors for advanced glycation end products. Implications for induction of oxidant stress and cellular dysfunction in the pathogenesis of vascular lesions. Arterioscler Thromb. 1994;14(10):1521-1528. http://dx.doi.org/10.1161/01.ATV.14.10.1521

37. Morgan PE, Dean RT, Davies MJ. Inactivation of cellular enzymes by carbonyls and protein-bound glycation/glycoxidation products. Arch Biochem Biophys. 2002;403(2):259-269. http://dx.doi.org/10.1016/S0003-9861(02)00222-9

38. Kawamura N, Ookawara T, Suzuki K, Konishi K, Mino M, Taniguchi N. Increased glycated $\mathrm{Cu}, \mathrm{Zn}$-superoxide dismutase levels in erythrocytes of patients with insulin-dependent diabetes mellitus. J Clin Endocrinol Metab. 1992;74(6):13521354.

39. Vasdev S, Ford CA, Longerich L, Gadag V, Wadhawan S. Role of aldehydes in fructose induced hypertension. Mol Cell Biochem. 1998;181(1-2):1-9. http:// dx.doi.org/10.1023/A:1006844222963

40. Suzuki T, Douard V, Mochizuki K, Goda T, Ferraris RP. Diet-induced epigenetic regulation in vivo of the intestinal fructose transporter Glut5 during development of rat small intestine. Biochem J. 2011;435(1):43-53. http://dx.doi.org/10.1042/ BJ20101987

41. Corpe $\mathrm{CP}$, Bovelander $\mathrm{FJ}$, Munoz $\mathrm{CM}$, et al. Cloning and functional characterization of the mouse fructose transporter, GLUT5. Biochim Biophys Acta. 2002;1576(12):191-197. http://dx.doi.org/10.1016/S0167-4781(02)00284-1

42. Litherland GJ, Hajduch E, Gould GW, Hundal HS. Fructose transport and metabolism in adipose tissue of Zucker rats: Diminished GLUT5 activity during obesity and insulin resistance. Mol Cell Biochem. 2004;261(1-2):23-33. http:// obesity and insulin resistance. Mol Cell Biochem.
dx.doi.org/10.1023/B:MCBI.0000028734.77867.d2

43. Nakayama T, Kosugi T, Gersch M, et al. Dietary fructose causes tubulointerstitial injury in the normal rat kidney. Am J Physiol Renal Physiol. 2010;298(3):F712-720. http://dx.doi.org/10.1152/ajprenal.00433.2009

44. Gersch MS, Mu W, Cirillo P, et al. Fructose, but not dextrose, accelerates the progression of chronic kidney disease. Am J Physiol Renal Physiol. 2007;293(4):F1256-1261. http://dx.doi.org/10.1152/ajprenal.00181.2007

45. Cirillo P, Gersch MS, Mu W, et al. Ketohexokinase-dependent metabolism of fructose induces proinflammatory mediators in proximal tubular cells. J Am Soc Nephrol. 2009;20(3):545-553. http://dx.doi.org/10.1681/ASN.2008060576

46. Lee FT, Cao Z, Long DM, et al. Interactions between angiotensin II and NF-kappaBdependent pathways in modulating macrophage infiltration in experimental diabetic nephropathy. J Am Soc Nephrol. 2004;15(8):2139-2151. http://dx.doi. org/10.1097/01.ASN.0000135055.61833.A8

47. Guder WG, Wagner S, Wirthensohn G. Metabolic fuels along the nephron: Pathways and intracellular mechanisms of interaction. Kidney Int. 1986;29(1):4145. http://dx.doi.org/10.1038/ki.1986.6

48. Ouali F, Djouadi F, Bastin J. Effects of fatty acids on mitochondrial beta-oxidation enzyme gene expression in renal cell lines. Am J Physiol Renal Physiol. 2002;283(2):F328-334. http://dx.doi.org/10.1152/ajprenal.00324.2001 
49. Pagliassotti MJ, Shahrokhi KA, Moscarello M. Involvement of liver and skeletal muscle in sucrose-induced insulin resistance: Dose-response studies. Am J Physiol. 1994;266(5 Pt 2):R1637-1644.

50. Taubes G. Good calories, bad calories. New York City: Knopf; 2007.

51. Wang H, Garvin JL, D'Ambrosio MA, Ren Y, Carretero OA. Connecting tubule glomerula feedback antagonizes tubuloglomerular feedback in vivo. Am J Physiol Renal Physiol. 2010;299(6):F1374-1378. http://dx.doi.org/10.1152/ajprenal.00403.2010

52. Grgic I, Campanholle G, Bijol V, et al. Targeted proximal tubule injury triggers interstitial fibrosis and glomerulosclerosis. Kidney Int. 2012;82(2):172-183. $\mathrm{http} / / / \mathrm{dx}$.doi.org/10.1038/ki.2012.20

53. Bonventre JV. Can we target tubular damage to prevent renal function decline in diabetes? Semin Nephrol. 2012;32(5):452-462. http://dx.doi.org/10.1016/j. semnephrol.2012.07.008

54. Szwergold BS, Kappler F, Brown TR. Identification of fructose 3-phosphate in the lens of diabetic rats. Science. 1990;247(4941):451-454. http://dx.doi.org/10.1126/ science. 2300805

55. Kawasaki T, Ogata N, Akanuma $\mathrm{H}$, et al. Postprandial plasma fructose level is associated with retinopathy in patients with type 2 diabetes. Metabolism. 2004;53(5):583-588. http://dx.doi.org/10.1016/j.metabol.2003.12.007

56. Boot-Handford R, Heath $\mathrm{H}$. Identification of fructose as the retinopathic agent associated with the ingestion of sucrose-rich diets in the rat. Metabolism. 1980;29(12):1247-1252. http://dx.doi.org/10.1016/0026-0495(80)90153-5

57. Glushakova $O$, Kosugi $T$, Roncal $C$, et al. Fructose induces the inflammatory molecule ICAM-1 in endothelial cells. J Am Soc Nephrol. 2008;19(9):1712-1720. http://dx.doi.org/10.1681/ASN.2007121304

58. Cohen AM, Teitelbaum A, Rosenman E. Diabetes induced by a high fructose diet. Metabolism. 1977;26(1):17-24. http://dx.doi.org/10.1016/0026-0495(77)90123-8

59. Cohen AM, Rosenmann E. Diffuse intercapillary glomerulosclerosis in sucrose-fed rats. Diabetologia. 1971;7(1):25-28. http://dx.doi.org/10.1007/BF02346250
60. Hotta N, Kakuta H, Fukasawa $\mathrm{H}$, et al. Effects of a fructose-rich diet and the aldose reductase inhibitor, ONO-2235, on the development of diabetic neuropathy in streptozotocin-treated rats. Diabetologia. 985;28(3):176-180.

61. Boot-Handford RP, Heath $\mathrm{H}$. The effect of dietary fructose and diabetes on the rat kidney. Br J Exp Pathol. 1981;62(4):398-406.

62. Sanchez-Lozada LG, Tapia E, Jimenez A, et al. Fructose-induced metabolic syndrome is associated with glomerular hypertension and renal microvascular damage in rats. Am J Physiol Renal Physiol. 2007;292(1):F423-429. http://dx.doi. org/10.1152/ajprenal.00124.2006

63. Shoham DA, Durazo-Arvizu R, Kramer $\mathrm{H}$, et al. Sugary soda consumption and albuminuria: Results from the National Health and Nutrition Examination Survey, 1999-2004. PLoS One. 2008;3(10):e3431. http://dx.doi.org/10.1371/journal. pone. 0003431

64. Saldana TM, Basso O, Darden R, Sandler DP. Carbonated beverages and chronic kidney disease. Epidemiology. 2007;18(4):501-506. http://dx.doi.org/10.1097/ EDE.0b013e3180646338

65. Bomback AS, Derebail VK, Shoham DA, et al. Sugar-sweetened soda consumption, hyperuricemia, and kidney disease. Kidney Int. 2010;77(7):609-616. http://dx. doi.org/10.1038/ki.2009.500

66. Lin J, Curhan GC. Associations of sugar and artificially sweetened soda with albuminuria and kidney function decline in women. Clin J Am Soc Nephrol. 2011;6(1):160-166. http://dx.doi.org/10.2215/CJN.03260410

67. Beddhu S, Kimmel PL, Ramkumar N, Cheung AK. Associations of metabolic syndrome with inflammation in CKD: Results from the Third National Health and Nutrition Examination Survey (NHANES III). Am J Kidney Dis. 2005;46(4):577-586. $\mathrm{http}: / /$ dx.doi.org/10.1053/j.ajkd.2005.06.014

68. Brymora A, Flisinski M, Johnson RJ, Goszka G, Stefanska A, Manitius J. Lowfructose diet lowers blood pressure and inflammation in patients with chronic kidney disease Nephrol Dial Transplant. 2012:27(2):608-612. http://dx.doi. org/10.1093/ndt/gfr223 